\title{
15. Multimodal academic argument in data visualization
}

\author{
Arlene Archer and Travis Noakes
}

\begin{abstract}
This chapter investigates the semiotic and rhetorical strategies for realizing argument in data visualizations produced by second-year journalism students. The semiotic strategies include use of colour, typography, graphics, and the rhetorical strategies include establishing credibility and the use of citation. The effect of the underlying basis for comparison of data on the argument is examined, as are the selection and processing of data. The chapter investigates the semiotic encoding of ideational material and the ways relationships are established within the discourse communities constructed in the data visualizations. This way of looking at academic argument has important implications for teaching these text-types in higher education in order to produce critical citizens; both in terms of production and critical analysis.
\end{abstract}

Keywords: Academic argument; Social semiotics; Data visualization; Higher education

\section{Introduction}

In an age in which more and more data are produced and circulated visually and digital environments make the production of data visualizations increasingly accessible, it is important to develop critical tools for people to engage with these kinds of texts. Data can be represented through a range of modes (such as writing, visuals, and numbers) and different data visualizations (from tables to graphs). There are design choices to be made in the production of these texts in terms of size, shape, colour, and composition in order to represent a particular argument to a particular

Engebretsen, M. and H. Kennedy (eds.), Data Visualization in Society. Amsterdam: Amsterdam University Press, 2020 DOI 10.5117/9789463722902_CH15 
audience in the most apt way. It is useful to analyse how this repertoire of semiotic resources works together, especially in terms of fulfilling specific functions in academic argument. These functions range from establishing logical relationships to constructing hypotheses. There is a need to develop a pedagogy that takes into account the functions of academic argument, as academic discursive conventions can serve as 'gatekeepers' in terms of student access (Prince \& Archer, 2008; Lea \& Street, 1998). This chapter explores a framework for looking at argument in data visualizations, and applies this to students' texts in a second-year journalism course. Student texts can highlight the constructed nature of academic argument through inconsistencies and disjunctures, thus exposing the normative practices of the discipline. Our analysis aims to identify semiotic signifiers of argument within data visualizations, in order to assist both in the production and critique of these kinds of texts.

\section{A social semiotic approach to argument in data visualizations}

Our approach to exploring argument is multimodal social semiotics, where meaning-making is seen as a social practice (Martinec \& van Leeuwen, 2008; van Leeuwen \& Jewitt, 2001). This approach has been shown to be productive in analysing a range of professional and pedagogical texts, such as technical drawings (Simpson, 2016), infographics (Prince \& Archer, 2014; Bateman, Wildfeuer, \& Hiippala, 2017), and PowerPoint slides (Zhao, Djonov, \& van Leeuwen, 2014). The assumption underpinning this approach is that meaning-making is informed by context. Also, meaning potentials are understood to be constructed through the selection and configuration of semiotic modes through the interests of the producer of the texts (Jewitt, 2009, p. 15). 'Mode' refers to socially and culturally shaped resources for making meaning, such as written language, spoken language, and visual representation (Kress, 2010). According to Halliday (1978), every sign performs three kinds of functions. The ideational function represents the world, concepts, and processes. The interpersonal function indexes the stance that the meaning-maker is taking towards audiences and the represented content. The textual function refers to the ways in which complexes of signs form coherent texts. In this metafunctional view, data visualization texts can represent a state of affairs, a relationship between abstract 'participants', and also indicate a particular relationship with an audience. These ideational and interpersonal aspects are realized through the textual organization or composition of the texts. 
A social semiotic approach can also help understand how writing and visuals work together in academic argument. A data visualization could, for instance, be used as evidence, it could be a part of an argument (the proposition, for instance), or it could constitute 'restatement' in a different mode. Sometimes, the communicative work of different modes in a text can complement each other, but they can also contradict each other. Where different modes realize different aspects in a complementary way, textual coherence may be achieved. However, where there is a disjuncture between the messages of the modes, coherence could be compromised. Recognizing the communicative work that modes are performing in a text is important in order for students to both critique and produce argument.

Academic argument is a semiotic practice which engages with ideas in the world and with the existing positions and conventions of a discipline (Coffin, 2009, p. 513). Broadly speaking, argument is a logical set of ideas that is supported by evidence. Evidence can be the existing accepted material that an 'arguer' agrees with, or resists, but nonetheless draws on to establish a position. Previously, one of us identified some underlying ways of organizing knowledge in multimodal argument, including narrative, induction, contrast, and comparison (Archer, 2016). Firstly, narrative structures can be used to represent sequencing in time, but also change from one state to another (Kress \& van Leeuwen, 2006). Secondly, induction or theorizing the relation of the particular to the general is another important structure. This can be both descriptive (backward-looking) and predictive (forward-looking). In other words, one can generalize from the specific instance, as well as make predictions about specific cases based on the general. Thirdly, academic argument can be realized through comparisons (both similarities and differences) and through contrast (where a juxtaposition sets up a tension between components of the text). Both comparisons and contrasts are based on underlying classifications according to specific categories. Clearly, this list is not exhaustive, but is useful in that it identifies structures of argument that work across modes. In general, we see argument as a textual form that produces 'difference' rather than closure (Kress, 1989). In foregrounding difference, argument can open the space for reconsideration, for a shift in values and attitudes, and for an extension of thought, producing 'new cultural values and knowledge' (Kress, 1989, p. 12). This notion of 'difference' offers insight into how tension is established in argument, particularly those based on comparison and contrast.

The chapter now moves on to propose a way of looking at argument in academic data visualization texts. It first investigates the semiotic encoding of ideational material in argument. Here the focus falls on the basis for 
comparison; the underlying discourses that are drawn on, and the ways these are realized using the resources of composition, colour, font, size, and shape. Secondly, the chapter explores the ways relationships are established within the discourse communities constructed in data visualizations, focusing on how credibility is established, and the use of citation.

\section{Semiotic encoding of ideational material in data visualizations}

The first ideational aspect to look at is the basis for comparison in an argument or the underlying classification for comparison. Selection and classification are always ideological. What is selected as well as the chosen basis for comparison is often as important as what is omitted. A second ideational aspect to explore is the normative discourses and practices that shape data visualizations. The analytical focus should thus fall on the analysis of semiotic resources (such as composition, shape, and colour) as located within the discourses, practices, and technologies that regulate the use of these resources. In recent social theory, discourse is understood to refer to the ways social institutions define and regulate the practices within those institutions. Discourses are 'socially constructed knowledges of (some aspect of) reality which give expression to the meaning and values of an institution or social grouping' (Kress \& van Leeuwen, 2001, p. 4). Discourses regulate the practices within those institutions through the use of language or other semiotic modes. Ledin and Machin (2016), for example, draw attention to the way 'strategic' diagrams recontextualize agents, processes, and causalities, and are often embedded in neoliberal discourses. It is also worthy of note that in some instances, normative discourses are built into the latest visual communication technologies, such as Microsoft PowerPoint or Excel (Zhao et al., 2014).

Data visualizations can be conceptualized in terms of van Leeuwen's (2008) 'new writing' as they encapsulate some of the principles of contemporary integrated design enabled by digital technology. This form of writing is 'at once more visual than the old "page" media, and less pictorial than the old "screen" media' (van Leeuwen, 2008, p. 132). Ideational content is encoded through the resources of composition, colour, font, size, and shape, as well as the choice of data visualization. For instance, bar charts compare quantities, pie charts show proportions of the whole, and line graphs show quantities over time.

In addition to looking at choices of semiotic resources, it is also important to look at the relations between image and writing. Many multimodality 
theorists have attempted to systematically describe visual/verbal relations (cf. Martinec \& Salway, 2005; Unsworth, 2006). In general, the relations between data visualization and writing can be thought of in terms of similarity, complementary, and opposition relations. In similarity relations, one could look at how one mode exemplifies the other. In complementary relationships, what is represented graphically and in writing may be different, but complementary. In opposition relations the content of the written text contrasts with that of the data visualization. Ideational and, at times, interpersonal content, are encoded through the relations between visual and written aspects, as well as through the semiotic choices of font, colour, size, shape, and compositional choices (of positionality and directionality).

\section{Establishing social relations in data visualizations}

The type of graphic chosen can establish credibility in argument and lend more authority to the numbers. Trimbur and Press (2015) argue that truth values ascribed to various modes are shaped by a struggle for rhetorical authority within the means of representation. Data visualizations tend to be assigned credibility as the assumptions underlying the numbers are generally hidden and numerical representations are often regarded as more factual and objective than other kinds of evidence (Porter, 1995; Zhou \& Hall, 2018). Whilst conveying results from questionnaires through statistical means enables participant anonymity, the existence of the participants then becomes masked by a number. The selection of data behind data visualization texts is of course subjective and every number can and should be interrogated. For this reason, it is important to cultivate a critical awareness (Kennedy et al., 2016) amongst both educators and students.

In academic writing, credibility in argument is often established through tentative assertions which are realized through discourse markers such as 'hedging' and 'emphatics' (Hyland, 1999, p. 104). Hedges indicate the writer's decision to withhold complete commitment, whereas emphatics construct certainty. What is of interest for data visualizations is the ways that credibility is established across the written and visual modes, and whether there is any 'hedging' or tentativeness in the representation of the data and the argument.

In Prince and Archer (2014) we argued that uncertainty about a 'point statistic' is often provided through the use of a 'confidence interval'. A confidence interval is a resource for representing a certain parameter and a range of possible values. This enables the presentation of findings in a 


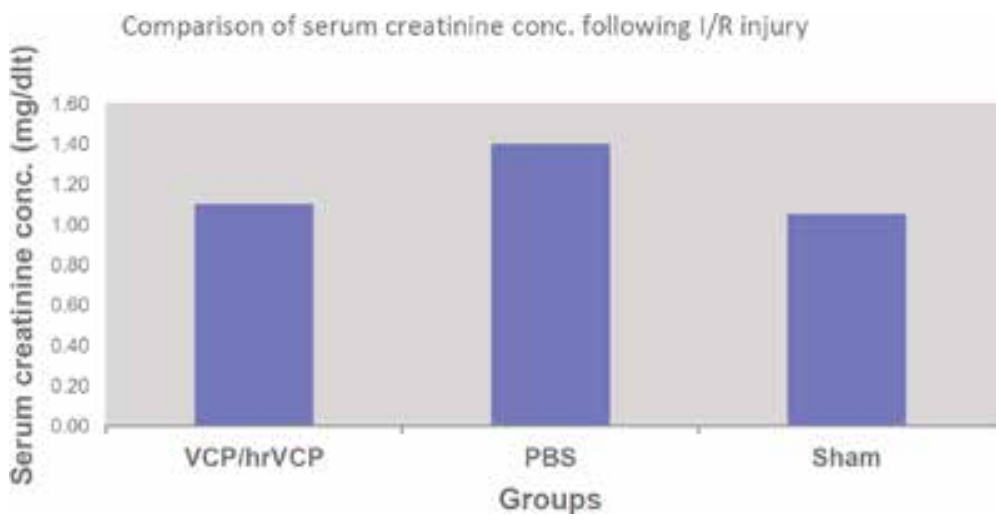

Figure 15.1a. Visual data hedging through the use of a confidence interval. Illustration by A. Archer \& T. Noakes.

\section{Comparison of serum creatinine conc.}

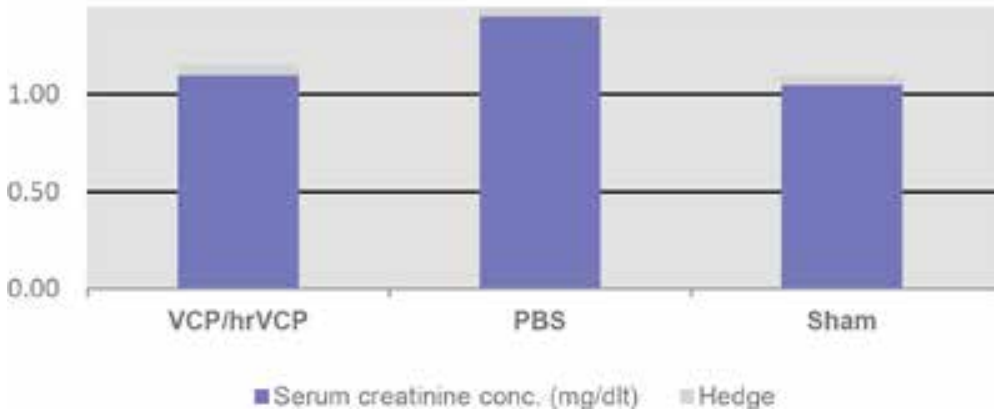

Figure 15.1b. An alternate visual form of hedging with maximum y-axis. Illustration by A. Archer \& T. Noakes.

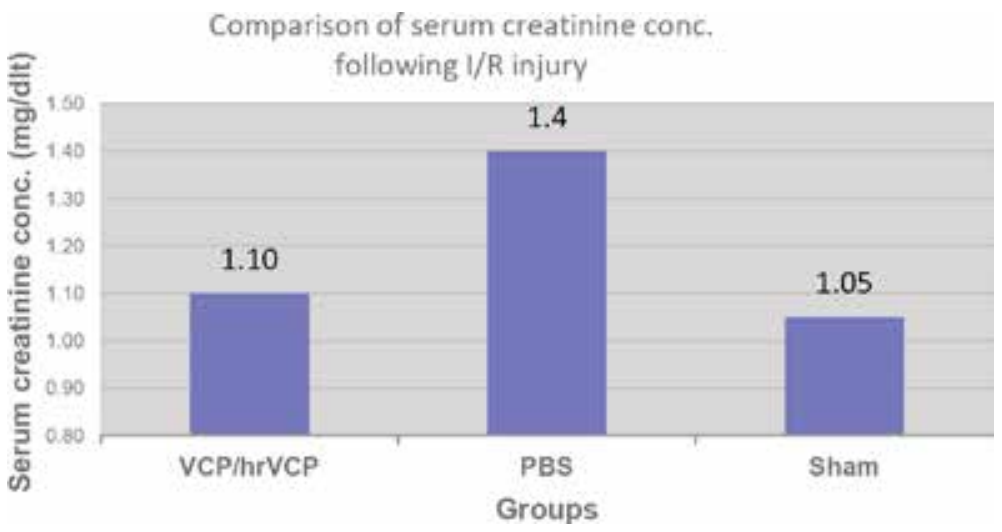

Figure 15.1c. Another visual form of hedging with the maximum and minimum values labelled. Illustration by A. Archer \& T. Noakes. 


\section{Comparison of serum creatinine conc. following I/R injury}

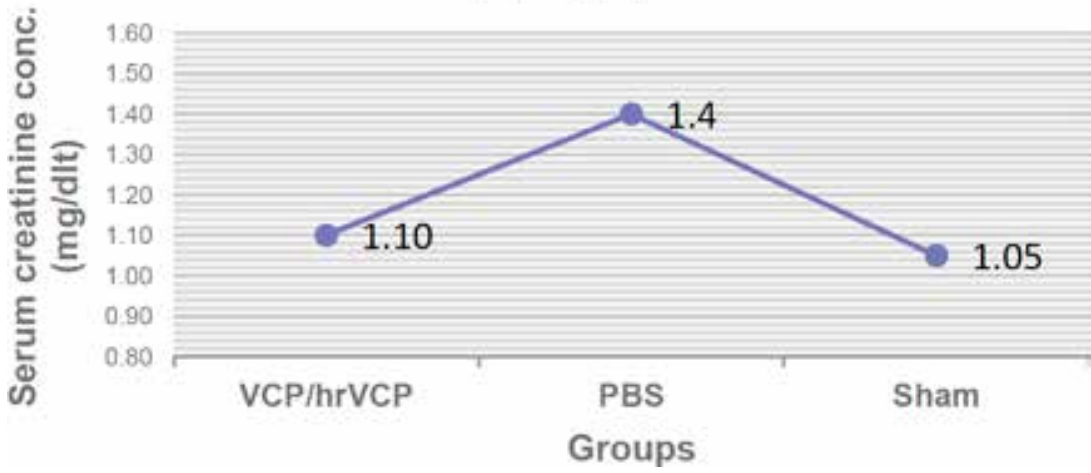

Figure 15.2. Maximum and minimum values indicated using separate line graphs. Illustration by A. Archer \& T. Noakes.

more tentative way, which can be likened to 'hedging' in academic discourse (see Figure 15.1a). Here the resources for indicating uncertainty include a line that spans the given point (both above and below it) to indicate the possible range of values. Other visual alternatives for indicating a confidence interval could include adding a second box chart (see Figure 15.1b), entering the range with data labels (see Figure 15.1c), or using separate line graphs to suggest the maximum and minimum ranges (see Figure 15.2).

Another way of establishing relations is the use of citation for appropriating a source into an argument and using the arguments of others to negotiate a position in a particular discourse community. All texts are always positioned in relation to a network of other texts. Choices about the integration of sources include the selection of material from the source, the form of the citation, and some kind of framing. There are a number of options for citation in data visualization. The data could be generated empirically by the researcher and thus no citation of external sources is necessary. A second possibility is the integration of a researcher's own data with cited data. Thirdly, data can be compiled from multiple sources within one information graphic. For example, data sources can be cited in a list at the bottom of a data visualization.

The placing of the in-text references in data visualizations is of importance. The source could be more foregrounded if placed in the label rather than the caption, for instance. In data visualizations, the words 'taken from...' could indicate the graphic is a reproduction or a 'quote' from the original source with all the deferment of authority that this entails. If the source is introduced as 'adapted from...' it indicates some kind of paraphrasing or 
reworking. The way in which the source is introduced is thus of importance. In writing, the 'reporting' verbs used to introduce a citation can be neutral (as in XX states), or sceptical (XX would have us believe), or strongly supportive of the source's position (XX has clearly demonstrated). The same kind of positioning does not necessarily occur in data visualizations as they are not always integrated with writing to the same extent. In sum, the choice of source, the reworking of the source in terms of paraphrasing, and the integration of the source all have implications for academic argument.

\section{Data visualization in a second-year journalism course}

We will now employ the framework outlined above to look at the semiotic and rhetorical strategies for realizing argument in data visualizations produced by second-year journalism students at a university in South Africa. The students were required to design a poster using data visualizations that focused on educational inequalities in two geographical areas in Cape Town (Noakes, 2017). Each student was taught to contrast up to three aspects of inequality within a poster design and to export the resulting text for blog publication. For the purposes of this chapter, all projects were reviewed as a convenience sample (Ferber, 1977) that would allow us to learn from the struggles of inexperienced students experimenting with data visualization design. Our research has provided input towards improving this pathfinder curriculum by incorporating ideas of multimodal argument.

As the task required, all the arguments in the student produced texts are based on comparisons, showing the differences in levels of education obtained in different geographical areas. Some students chose to focus on social issues (such as pregnancy, poverty, single- or no-parent households) and others on access issues (internet, home language, unemployment, income). Here we look at two of the posters produced. The students gave permission for their work to be discussed and they understand that we are drawing attention to both the successful and unsuccessful aspects of argument through visualization. The first poster highlights the difficulty of producing argument rather than description, and the second one showcases the struggle between causation and correlation in these types of texts.

\section{Description versus Argument}

The data visualization poster in Figure 15.3 compares two areas in Cape Town that feature vastly different living circumstances, namely Nyanga 


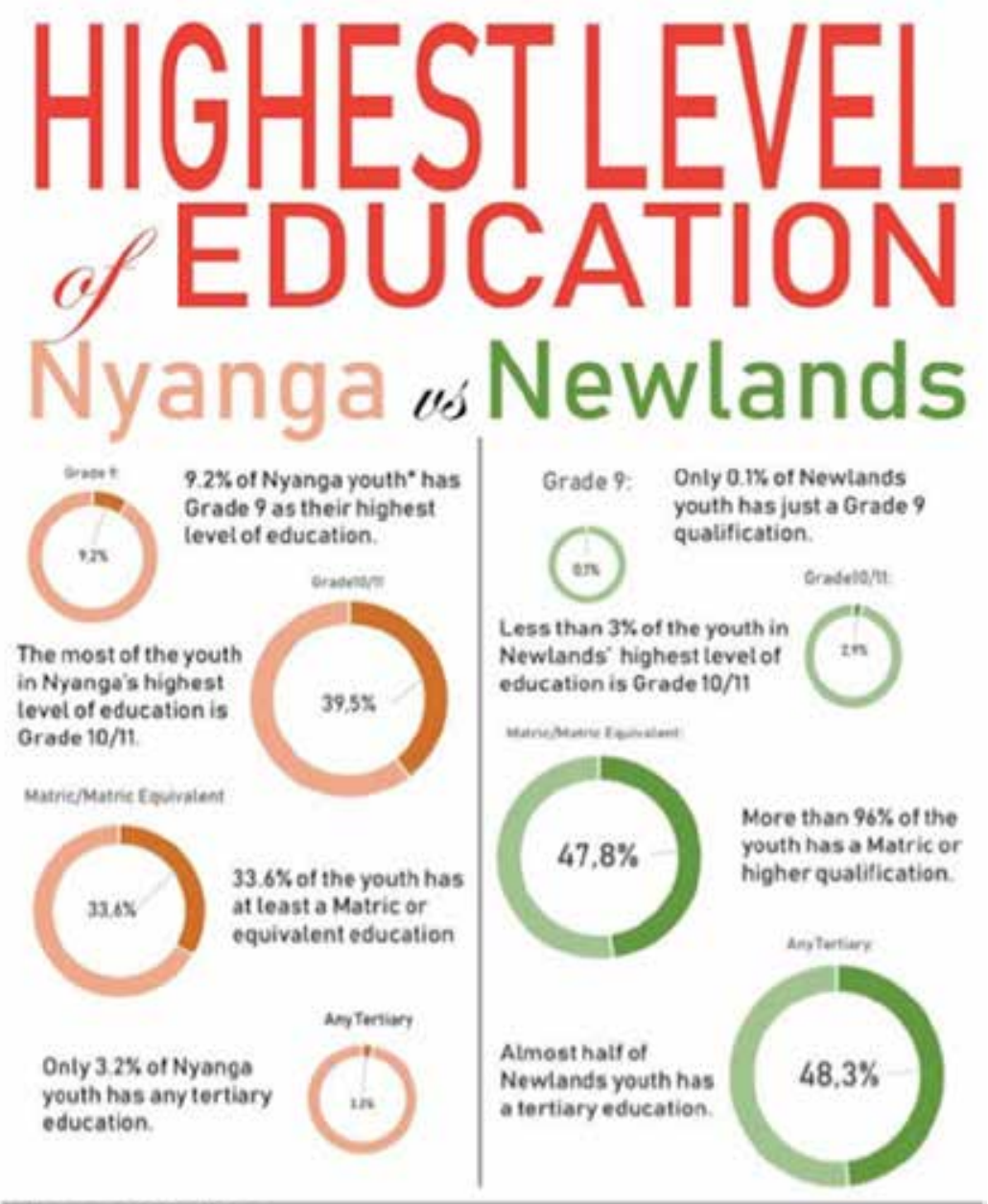

\section{Research findings}

Although the youth population in the Newlands ward and the Nyanga ward is about the same, the average highest levet ef educatien in Nrwlands is substantially Nigher than that seen in Nranga.

Many youth from Newlands entered inte tertiary edvcatien but the routh trom hyanja rarely entwred univeraily, The kigh scheod drep-eut rate in Niyanga is much higker than in Newiands.

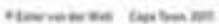

Figure 15.3. Nyanga versus Newlands. Poster by E. van der Walt, 2017. Reprinted with permission.

and Newlands. Nyanga is a predominantly 'black' township situated about $26 \mathrm{~km}$ from the city centre. It is one of the poorest areas in Cape Town and has a high unemployment rate. Newlands, on the other hand, is an upmarket suburb located at the foot of Table Mountain. It has many good schools and sports and recreation facilities. The poster compares the highest level of education achieved by the youth in each area (Grade 12 refers to the final year of schooling). The poster tends towards description rather than argument, 
as it does not identify possible contributing factors for the difference in educational performance in Nyanga and Newlands.

The basis for contrast is stated as: 'the youth population in the Newlands ward and the Nyanga ward is about the same'. In fact, according to the youth explorer website, there are 4,648 youth in Nyanga and 3,765 in Newlands, so the word 'about' is rather a larger qualifier. This discrepancy aside, making the number of youths the underlying basis for contrast could serve to efface and neutralize the vast differences between the areas. What is not stated, for example, is that Nyanga is $1.2 \mathrm{~km}$ squared whereas Newlands is $44.1 \mathrm{~km}$ squared, making the youth per square $\mathrm{km}$ in Nyanga 4,018.3 as compared to 85.4 youth per square kilometre in Newlands (youthexplorer.org.za).

The underlying structure of the argument is a binary where two aspects are juxtaposed. The contrast is set up visually through two main resources, namely layout and colour. In terms of layout, the poster is divided by a vertical line into two sections, Nyanga on the left and Newlands on the right. In terms of colour, van Leeuwen (2008) points out that colour can be used both for its connotative potential and to signify textual cohesion. The poster employs colour to signify particular features of the two areas as well as to establish the contrast. The title 'Nyanga' and the data related to Nyanga are depicted in a 'rusty red' or orange, emphasizing the dryness (dust), less development, and poor infrastructure of the area. This is opposed to the green of Newlands which points to the notion of the 'leafy suburb', as well as natural beauty (the forest and nature of this high rainfall area). Other design choices in the poster include one simple graph type throughout, a 'donut' chart. The poster uses size as a semiotic resource in argument: sizing the graphs in accordance with their percentage values, and the font sizes get bigger for larger percentages.

A citation is placed at the bottom right corner of the poster in the form of a URL, the 'youth explorer' website (https://youthexplorer.org.za). Such a citation may lack credibility in not actually citing the originating source of the data (the Western Cape Education Department). A similar issue occurs where students have attributed image sources in their presentations to 'Google', the search engine. A critical reader would expect to be able to use the link to directly access the attributed images, much as website database references should refer directly to their sources, not to aggregators or search engines that are intermediaries.

The poster establishes credibility by employing the academic discourse conventions of hedging ('about') and qualified emphatics ('substantially'). Credibility is also established by presenting the 'research findings' dispassionately as facts: 
Although the youth population in the Newlands ward and the Nyanga ward is about the same, the average level of education in Newlands is substantially higher than that seen in Nyanga. Many youth from Newlands entered into tertiary education, but the youth from Nyanga rarely entered university. The high school drop-out rate in Nyanga is much higher than in Newlands.

However, it would appear that information is presented here, rather than argued, as the underlying causes for this vast disparity are not identified. This objective presentation of 'facts' could serve to erase the people and the hardships of the area (from overcrowding to crime).

\section{Correlation versus causation}

In Figure 15.4, the data visualization text attempts to make an argument. It hypothesizes the underlying causes for the differentials in education levels achieved in the two chosen areas that roughly encompass Camps Bay (Ward 54) and Hout Bay (Ward 74). The poster attempts to look at factors for academic exclusion. It provides an explanation for the potential exclusionary role of language, and a link is made between internet access and academic throughput.

The student claims to have chosen these two areas as they are 'neighbouring' wards in close proximity to each other. Whereas Camps Bay is a more affluent area along the Atlantic seaboard, Hout Bay is a somewhat demographically mixed area. Once a more homogenously upmarket area, Hout Bay now includes a large informal settlement, Imizamo Yethu, which was established about 25 years ago. The area houses approximately 33,60o people in high density living. However, the complexity of the demographics and history of Hout Bay cannot be reflected here in a simplistic contrast with Camps Bay, as was the task brief.

The poster is divided into three sections, using a band of colour in the middle to separate the sections. Colour is employed predominantly as an organizational feature, rather than for its connotational affordances, and shades of purple and orange dominate. Blue is used for Ward 74 and orange for Ward 54 in the charts. While the student has chosen these colours to tie in with the pallet of her painter logo, the orange, blue, and white colours used may upset viewers who could perceive this as a reference to the colour of the Apartheid-era South African flag. However, as a non-South African student, it is unlikely that she was aware of the 


\section{Language, Education, and Internet Access in neighboring wards of Cape Town}
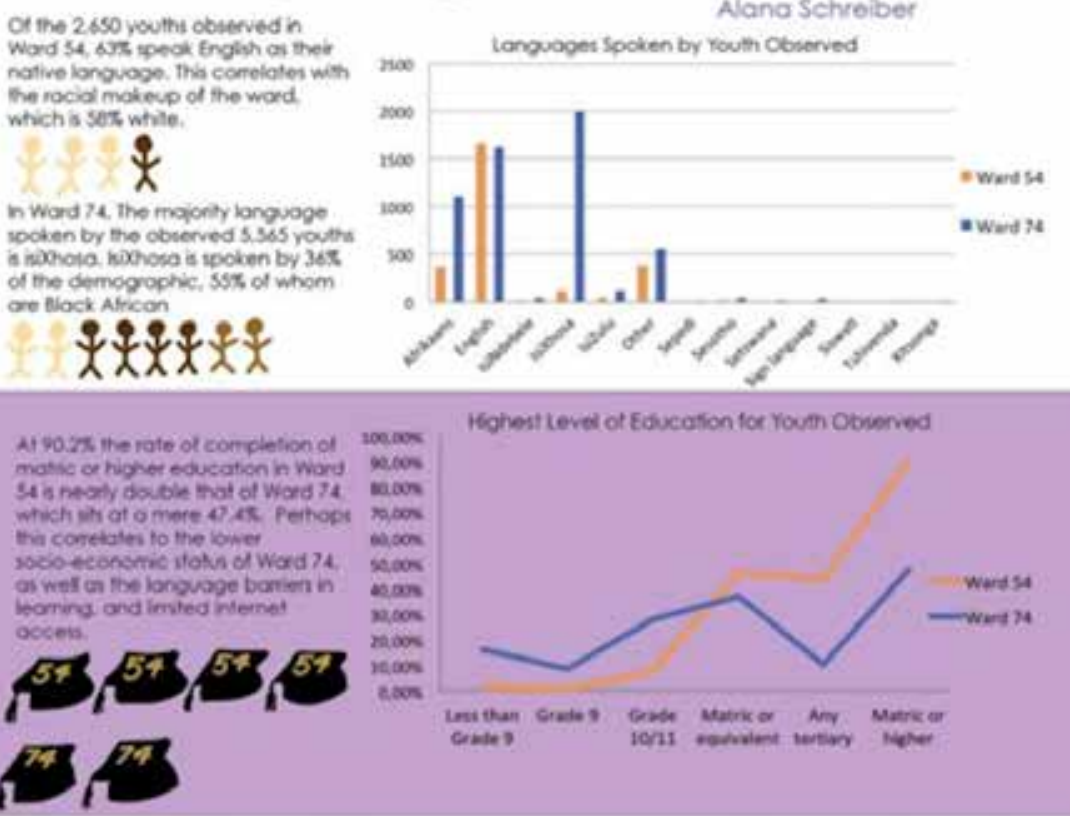

While orly $11,0 \pi$ of the demograptic in Word st has no consitont internet occess amost holl of the demogrophic is without occess in Word 74 . Imiled access to inter. net con create severe obstocies for higher educaken and lob oporturitist

Nhovgh counotion connof be delen. mined. there appean to be a cortelation betmeen borten n longuoge and inier. net-and other facton ike weath and roce - frat imber the roults in Ward 74 from more attoining occess to hicher edy. cotion fipecioly when compored to hey privleged neighbon in ward 34
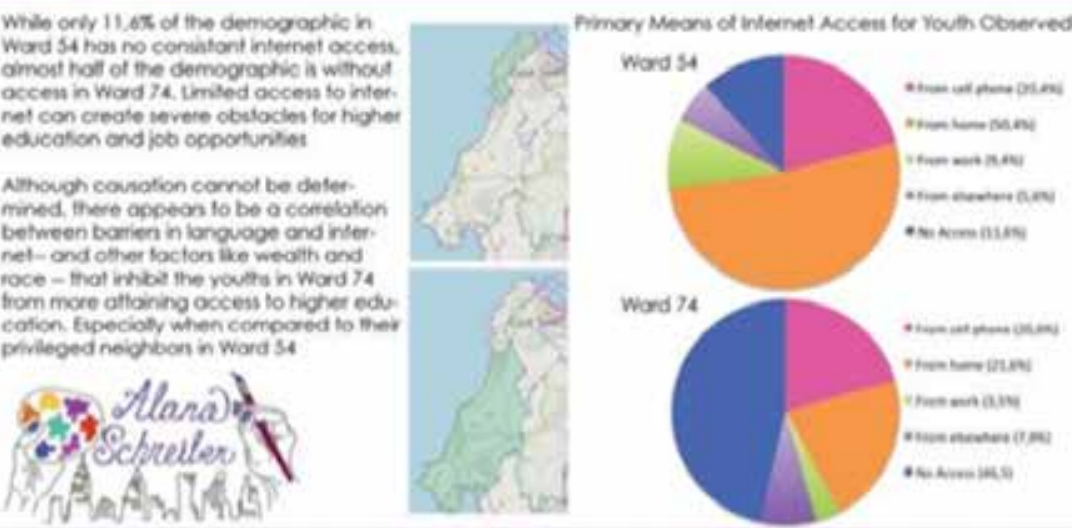

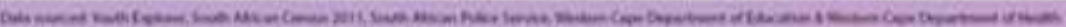

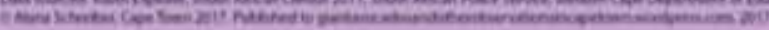

Figure 15.4. Language, Education and Internet Access in neighbouring wards of Cape Town: Camps Bay versus Hout Bay. Poster by Alana Schreiber, 2017. Reprinted with permission.

negative connotations of this choice. The stark contrast in achievement of higher education (90.2 percent versus 47.4 percent) is indicated visually by the blue and orange lines. This is echoed in the writing on the left side, which states: 
At $90.2 \%$ the rate of completion of matric or higher education in Ward 54 is nearly double that of Ward 74 , which sits at a mere $47.4 \%$. Perhaps this correlates to the lower socio-economic status of Ward 74, as well as the language barriers in learning, and limited internet access.

The writing here establishes credibility through the use of hedges ('nearly') and tentative statements ('perhaps') which is in accordance with conventions of academic discourse. However, it is not a dispassionate representation of 'facts' as indicated by a 'mere $47.4 \%$ ' which indicates surprise or some outrage at the low figures.

A simplified visual is used to restate the written argument (namely, four 'ward 54' graduation hats placed above two 'ward 74' graduation hats). These graduation hats indicate the notions of half and double without being statistically accurate. The use of the graduation hat graphics alongside the line chart in the poster could be seen to be the equivalent of first and third person in data visualization texts. While third person writing often characterizes research that uses both qualitative and quantitative methods, Zhou and Hall suggest incorporating more of the first person, as they claim this 'adds to the subjective experience as part of the evidence for the author's claims and makes the author's perspective and constructive role in creating meaning in a study more visible' $(2018$, p. 2$)$. As with the graduation hats, the rows of figures at the top left of the poster show the demographics of each area, but not in any statistically accurate way. These kinds of simplified representations may be a way of reintroducing narrative and experience into data visualization.

The bottom band of the poster compares the internet access of the two areas. While the student accedes that internet access is not causal in educational achievement, she suggests that there is a correlation.

Although causation cannot be determined, there appears to be a correlation between barriers in language and internet - and other factors like wealth and race - that inhibit the youths in Ward 74 from more attaining access to higher education. Especially when compared to their privileged neighbours in Ward 54 .

The explanation for the internet's role assumes that the internet is used during school assignments. However, this is seldom the case, especially at government schools that first-language isiXhosa speakers would typically attend. The academic argument here is mostly made through written text, and not through data visualization. The poster samples quite disparate 
datasets ('level of education', 'language', and 'internet access'), which require written explanation. The writing thus serves to make links between the graphs, and then to summarize the argument. The argument is realized effectively, however, through the juxtaposition of pie charts, creating 'difference', and through the writing, which communicates a sense of outrage by using words like 'inhibit' and 'privileged'. Here, Kress's (1989) notion that argument foregrounds difference is pertinent, as this juxtaposition opens the space for reconsideration, for a shift in values and attitudes, even if correlation and causation become slightly blurred in the representation.

\section{Discussion and implications}

The past three years in South African higher education have seen a growing movement known as '\#feesmustfall', which was unprecedented in its scale and violence (Jansen, 2017) in calling for free, decolonized education (Ndlovu, 2017). Disparities in access to higher education as residual effects of the apartheid system and a slow and disproportionate throughput of students are part of the reasons for the \#feesmustfall movement and the call to decolonize higher education. This forms part of the circulating discourses and contexts in which the students produced these data visualization texts. In fact, at the time the students were to present their posters, lectures were cancelled due to protest action, and students were given the option to submit a PowerPoint presentation together with an audio file. This context highlights the need for students to become critical users, assessors, and producers of scientifically grounded data visualizations, with an understanding of the surrounding discourses.

Despite access to higher education being of topical importance, the type of data provided via youthexplorer.org.za does not currently support students to design posters that might contextualize these issues. For example, the site does not provide data on academic access in local universities, nor drop-out rates in degrees. Youthexplorer.org.za's data come from a particular governmental discourse with particular values that organizes and selects 'important' data on youths made available to site users. It is important to understand what a discourse focused on the state's role for improving the wellbeing of young people neglects, such as promoting equitable access to tertiary education.

On a more specific level, the students tended to confuse correlation and causation, such as, assuming that internet access supports a high pass rate. Rather, in the South African context, internet access is a marker of 
privilege that is often linked to households that can afford better schooling. In addition, the data visualizations did not really allow for blurred categories as each data point needs to be assigned to a separate category. Data visualizations tend to simplify qualitative complexity into a number. For example, studying or a 'gap year' or any other reason for not working often fell under the category of 'unemployment' in the data visualizations. Data visualization is thus often a simplification of complexity. To enable students to read and produce argument, we need to develop an awareness of processes of simplification in order to inculcate a critical perspective on meaning-making.

This chapter has highlighted what Kennedy and Hill (2017) call the 'complex entanglement' of aspects of data visualization: knowing how to physically create these texts; the underlying discourses and ideological work of data visualizations; and the pleasure and aesthetics of data visualization. We have presented an analysis of two data visualization texts in an attempt to explore how academic argument is constructed through the interplay between multiple semiotic resources. Written language, visual representation, and the representational choices we make (like using a bar rather than a point on a graph) all contribute to academic argument. We have shown how, in composing data visualizations, students encode ideational material and establish relationships within the discourse community, both through citation and establishing credibility. A way of looking at academic argument such as the one explored here could be useful to facilitate awareness and analysis of data visualization texts for students in order to enable access to their invisible norms and conventions. The discourses that shape data visualizations are expressed through choice, such as the type of representation and the composition of the representation. Producing these data visualizations can facilitate recognition of the social provenance of texts, namely that data visualizations are often seen as objective and neutral, rather than ideological. We have fed these insights back into this particular journalism course. However, this chapter has argued that this has important implications for the way we teach these text types in higher education in general in order to produce critical citizens, both in terms of production and critical analysis.

\section{Acknowledgements}

The research is based upon work supported by the British Academy Newton Advanced Fellowship scheme. 


\section{References}

Archer, A. (2016). Multimodal academic argument: Ways of organizing knowledge across writing and image. In: A. Archer \& E. Breuer (Eds.), Multimodality in Higher Education. (pp. 93-113). Leiden: Brill.

Bateman, J., Wildfeuer, J., \& Hiippala, T. (2017). Multimodality:

Foundations, research and analysis-A problem-oriented introduction. Berlin: De Gruyter Mouton.

Coffin, C. (2009). Contemporary educational argumentation: A multimodal perspective. Argumentation, 23(4), 513-530. https://doi.org/10.1007/s10503-009-9161-z Ferber, R. (1977). Research by convenience. Journal of Consumer Research, 4(1), 57-58. http://dx.doi.org/10.1086/208679

Halliday, M. A. K. (1978). Language as social semiotic: The social interpretation of language and meaning. London: Arnold.

Hyland, K. (1999). Disciplinary discourses: Writer stance in research articles. In: C. N. Candlin \& K. Hyland (Eds.), Writing: Texts, processes and practices. (pp. 99-121). London \& New York: Longman.

Jansen, J. (2017). As by fire: The end of the South African university. Cape Town: Tafelberg.

Jewitt, C. (Ed.). (2009). The Routledge handbook of multimodal analysis. Abingdon \& New York: Routledge.

Kennedy, H., Hill, R. L., Allen, W., \& Kirk, A. (2016). Engaging with (big) data visualizations: Factors that affect engagement and resulting new definitions of effectiveness. First Monday, 21(11). https://doi.org/10.5210/fm.v21i11.6389

Kress, G. (2010). Multimodality: A social semiotic approach to contemporary communication. London \& New York: Routledge.

Kress, G. (1989). Texture and meaning. In: R. Andrews (Ed.), Narrative and argument. (pp. 9-21). Milton Keynes: Open University Press.

Kress, G., \& van Leeuwen, T. (2006). Reading images: The grammar of visual design (2nd ed.). London: Routledge.

Kress, G., and van Leeuwen, T. (2001). Multimodal discourse: The modes and media of contemporary communication. London: Arnold.

Lea, M. R., \& Street, B. (1998). Student writing in Higher Education: An academic literacies approach. Studies in Higher Education, 23(2), 157-172. http://doi.org/1 0.1080/03075079812331380364

Ledin, P., \& Machin, D. (2016). Strategic diagrams and the technologization of culture. Journal of Language and Politics, 15(3), 322-336. https://doi.org/10.1075/ jlp.15.3.o6led 
Martinec, R., \& Salway, A. (2005). A system for image-text relations in new (and old) media. Visual Communication 4(3), 337-371. https://doi.org/10.1177/14703 57205055928

Martinec, R., \& van Leeuwen, T. (2008). The language ofnew media design: Theory and practice. London \& New York: Routledge.

McCandless, D. (2009). Information is beautiful. London: Collins.

Ndlovu, M. (2017). \# FeesMustFall and youth mobilisation in South Africa: Reform or revolution? Abingdon: Routledge.

Noakes, T. (2017). Designing infographics on educational inequalities in Cape Town's wards-a new \#UCT Media Studies project. Retrieved August 31, 2018 from http:// www.travisnoakes.co.za/2017/11/designing-infographics-on-educational.html

Porter, T. M. (1995). Trust in numbers: The pursuit of objectivity in science and public life. Princeton, NJ: Princeton University Press.

Prince, R., \& Archer, A. (2008). A New Literacies approach to academic numeracy practices in Higher Education in South Africa. Literacy and Numeracy Studies, 16(1), 63-75.

Prince, R., \& Archer, A. (2014). Exploring academic voice in multimodal quantitative texts. Literacy and Numeracy studies, 22(1), 39-57.

Simpson, Z. (2016). 'Drawn Writing': The role of written text in civil engineering drawing. In: A. Archer \& E. O. Breuer (Eds.), Multimodality in Higher Education. (pp. 241-255). Leiden: Brill.

Trimbur, J., \& Press, K. (2015). When was multimodality? Modality and the rhetoric of transparency. In: A. Archer \& E. Breuer (Eds.), Multimodality in writing: The state of the art in theory, methodology and pedagogy. (pp. 17-42). Leiden: Brill.

Unsworth, L. (2006). Towards a metalanguage for multiliteracies education: Describing the meaning-making resources of language-image interaction. English Teaching: Practice and Critique, 5(1), 55-76.

van Leeuwen, T. (2008). New forms of writing, new visual competencies. Visual Studies, 23(2), 130-135. https://doi.org/10.1080/14725860802276263

van Leeuwen, T., \& Jewitt, C. (Eds.). (2001) Handbook of visual analysis. London: Sage Publications; New Delhi: Thousand Oaks.

Youth Explorer. (2011). About Youth Explorer. Retrieved August 31, 2018 from https:// youthexplorer.org.za/about

Zhao, S., Djonov, E., \& van Leeuwen, T. (2014). Semiotic technology and practice: A multimodal social semiotic approach to PowerPoint. Text \& Talk, 34(3), 349-375. Zhou, X., \& Hall, J. (2018). Mixed methods papers in first-person and third-person: Writing voices in dialogue. Journal of Mixed Methods Research, 12(3), 344-357. https://doi.org/10.1177/1558689816652755 
About the author

Arlene Archer, PhD, is an Associate Professor in Applied Linguistics. She is the director of the Writing Centre at the University of Cape Town and leads the South African Multimodality in Education group.

Travis Noakes is an Honorary Research Associate at the Centre for Film and Media, University of Cape Town. His research interest is describing young adults' diverse strategies and productions as online content creators. 